\title{
Comentário
}

\section{Monitorar o futuro: a próxima geração de estudos populacionais sobre álcool e drogas no Brasil}

O debate sobre álcool e drogas no Brasil tem sido alimentado muito mais pelo calor da paixão ou do pânico moral do que pela frieza da razão e dos dados empíricos. A sociedade no geral e a mídia escrita e televisiva em particular buscam capturar evidências da dimensão do consumo de drogas e muitas vezes acabam somente criando um clima de desamparo frente a um problema que aparentemente é inevitável. Felizmente algumas iniciativas têm servido para colocar um pouco mais de ordem neste debate. O trabalho do Cebrid (Centro Brasileiro de Informações sobre Drogas Psicotrópicas) que, ao longo de mais de dez anos, produziu quatro levantamentos sobre o uso de drogas entre estudantes do primeiro e segundo graus em 10 capitais brasileiras é um exemplo de determinação e busca de informações fundamentais no planejamento de ações futuras. Esses levantamentos serviram para determinar a tendência de consumo dos estudantes e dissipar alguns mitos importantes como o de que as drogas mais consumidas não são as ilícitas, mas sim as lícitas como o fumo e o álcool.

Felizmente podemos falar que agora entramos numa segunda fase desses estudos epidemiológicos, que tendem a ser mais analíticos e buscam entender um pouco mais do que se passa entre nossos jovens. Dois bons exemplos desses estudos são publicados nesta edição. Scivoletto e col., através de um financiamento generoso por parte da Fapesp (Fundação de Amparo à Pesquisa do Estado de São Paulo), fizeram uma análise do consumo de drogas entre estudantes e sua relação com a sexualidade. Mostraram que os usuários de drogas tinham: início mais precoce das relações sexuais; maior número de relações; pagavam mais por sexo e faziam um menor uso de preservativos. Dados fundamentais no planejamento de futuras ações em programas de prevenção com este tipo de população. Kerr-Corrêa e col. investigaram o uso de drogas entre estudantes da Faculdade de Medicina de Botucatu e comparou-os com o comportamento de estudantes de outras oito escolas médicas do Estado de São Paulo. Confirmaram o que Guerra de Andrade já havia mostrado anteriormente: que o consumo cresce do primeiro ao sexto ano. As prevalências são preocupantes: uso de solventes $(8 \%)$, maconha $(6 \%)$, benzodiazepínicos $(3 \%)$, cocaína $(0,5 \%)$ e anfetaminas $(1 \%)$. A única boa notícia parece ser que o consumo de tabaco, ao redor de 7\%, é bem menor quando comparado ao da população em geral. A sugestão feita pelos autores de que é necessá- rio um programa mais coordenado e agressivo para esta população ninguém poderá questionar.

Embora não estejam nesta edição, dois outros estudos merecem ser mencionados. Um deles, coordenado por Sérgio de Paula Ramos, do Hospital Mãe de Deus, de Porto Alegre, foi um projeto chamado Valorização da Vida, que buscou fazer uma intervenção num grupo de 18 colégios que tinham alunos do primeiro ano de primeiro grau ao terceiro ano do segundo grau. Esses colégios foram divididos em dois grupos, um experimental e um controle, e foram avaliados por pesquisadores independentes. Ficou demonstrado que no grupo experimental houve uma redução do consumo de drogas de $11 \%$ em relação ao controle, dois anos após o começo do estudo. Um outro estudo, também em escolas, foi feito por Dalgalarrondo e Saldera da Unicamp. Eles compararam 2.290 estudantes de escolas públicas e privadas da região de Campinas e fizeram uma análise detalhada e multivariada de vários fatores que estariam contribuindo para o consumo de drogas. Mostraram como o componente religioso estaria agindo como um fator importante para a prevenção do consumo de drogas.

Nos EUA o governo financia inúmeros programas com o objetivo de obter informações sobre tendências de consumo de drogas entre diferentes populações e o que realmente funciona nas intervenções nas escolas. Um desses programas chama-se "Monitoring the Future" e visa entender o comportamento dos jovens americanos, tendo em mente quais ações atuais irão evitar que mais uma geração de americanos sofra com as drogas. No Brasil estamos longe de termos uma ação governamental integrada e séria. As primeiras manifestações da recém-criada Senad (Secretaria Nacional Antidroga) parece servir mais como uma manifestação de mídia do que uma política consistente.

Através desses estudos, que estão sendo feitos por vários grupos de pesquisadores de diferentes universidades, estamos começando, a duras penas e com pouca ajuda governamental, a monitorar o futuro de nossas populações mais jovens e criando a sensação de que não existe nada de inevitável no uso de drogas por essa população.

Ronaldo Laranjeira Professor Adjunto do Departamento de Psiquiatria da Unifesp / EPM 